\title{
Changing patterns of urologic emergency visits and admissions during the COVID-19 pandemic: a retrospective, multicenter, nationwide study
}

\author{
Pawel Rajwa ${ }^{1}$, Mikolaj Przydacz ${ }^{2}$, Wojciech Krajewski ${ }^{3}$, Blazej Kuffel ${ }^{4}$, Piotr Zapala ${ }^{5}$, \\ Aleksandra Krzywon ${ }^{6}$, Alexander J. Cortez ${ }^{6}$, Bartosz Dybowski ${ }^{7}$, Remigiusz Stamirowski ${ }^{8}$, \\ Marcin Jarzemski ${ }^{9}$, Rafal B. Drobot ${ }^{10}$, Pawel Stelmach ${ }^{11,12}$, Krystyna Mlynarek ${ }^{13}$, \\ Mateusz Marcinek ${ }^{14}$, Maciej Przudzik ${ }^{15}$, Wiktor Krawczyk ${ }^{8}$, Jakub Ryszawy ${ }^{1}$, Dominik Choragwicki², \\ Lukasz Zapala ${ }^{5}$, Marcin Lipa ${ }^{10}$, Michal Pozniak ${ }^{4}$, Dawid Janczak ${ }^{11,12}$, Szymon Słomian ${ }^{13}$, \\ Jan Łaszkiewicz ${ }^{3}$, Marcel Nowak ${ }^{14}$, Marcin Miszczyk ${ }^{16}$, Marek Roslan ${ }^{15}$, Michał Tkocz ${ }^{14}$, \\ Romuald Zdrojowy ${ }^{3}$, Andrzej Potyka ${ }^{13}$, Tomasz Szydełko ${ }^{11,12}$, Tomasz Drewa ${ }^{4}$, Piotr Jarzemski ${ }^{9}$, \\ Piotr Radziszewski ${ }^{5}$, Marcin Slojewski ${ }^{8}$, Artur Antoniewicz ${ }^{10}$, Andrzej Paradysz ${ }^{1}$, Piotr L. Chlosta ${ }^{2}$
}

${ }^{1}$ Department of Urology, Medical University of Silesia, Zabrze, Poland ${ }^{2}$ Department of Urology, Jagiellonian University Medical College, Krakow, Poland ${ }^{3}$ Department of Urology and Urological Oncology, Wroclaw Medical University, Wroclaw, Poland

${ }^{4}$ Department of General and Oncological Urology, $1^{\text {st }}$ University Hospital, Nicolaus Copernicus University, Bydgoszcz, Poland

${ }^{5}$ Department of General, Oncological and Functional Oncology, Medical University of Warsaw, Warsaw, Poland

${ }^{6}$ Department of Biostatistics and Bioinformatics, Maria Skłodowska-Curie National Research Institute of Oncology, Gliwice Branch, Gliwice, Poland

'Department of Urology, Roefler Memorial Hospital, Pruszkow, Poland

${ }^{8}$ Department of Urology and Urological Oncology, Pomeranian Medical University,

Szczecin, Poland

${ }^{9}$ Department of Urology, Jan Biziel University Hospital in Bydgoszcz, Nicolaus

Copernicus University in Torun, Collegium Medicum in Bydgoszcz, Poland

${ }^{10}$ Department of Urology and Urological Oncology, Multidisciplinary Hospital

in Warsaw-Miedzylesie, Warsaw, Poland

${ }^{11}$ Clinical Department of Urology, $4^{\text {th }}$ Clinical Military Hospital, Wroclaw, Poland

${ }^{12}$ Division of Oncology and Palliative Care, Faculty of Health Sciences,

Wroclaw Medical University, Poland

${ }^{13}$ Urological Ward, Independent Public Health Care Unit, Voivodeship Specialised Hospital No. 3, Rybnik, Poland

${ }^{14}$ Department of Urology, FMS in Katowice, Medical University of Silesia, Katowice, Poland

${ }^{15}$ University of Warmia and Mazury, Faculty of Medicine, Department of Urology, Olsztyn, Poland

${ }^{16}$ Maria Skłodowska-Curie National Research Institute of Oncology, Gliwice Branch, Gliwice, Poland

Submitted: 7 July 2020; Accepted: 28 July 2020

Online publication: 25 August 2020

Arch Med Sci 2021; 17 (5): 1262-1276

DOI: https://doi.org/10.5114/aoms.2020.98364

Copyright $\odot 2020$ Termedia \& Banach

\section{Abstract}

Introduction: We aimed to examine the change in the number and severity of visits to the emergency departments (EDs) and subsequent admissions for urgent urologic conditions in the early stage of the coronavirus disease 2019 (COVID-19) pandemic in Poland.

Material and methods: We evaluated data from 13 urologic centers in Poland and compared the number of visits to the EDs and subsequent admis-

\author{
Corresponding author: \\ Pawel Rajwa MD, PhD \\ Department of Urology \\ Medical University of Silesia \\ 3-go Maja Street 14-15 \\ 41-800 Zabrze, Poland \\ Phone: +48 323704454 \\ E-mail: pawelgrajwa@gmail. \\ com
}


sions before and after the advent of COVID-19 in 2020, and before and after the escalating national restrictions. Furthermore, data on types of urologic complaints, crucial laboratory parameters, and post-admission procedures were analyzed.

Results: In total 1,696 and 2,187 urologic visits (22.45\% decrease) and 387 and 439 urologic urgent admissions (11.85\% decrease) were reported in given periods in 2020 and 2019, respectively. The year-over-year difference in daily mean visits was clear (36.1 vs. $46.5 ; p<0.001)$. Declines were seen in all complaints but device malfunction. In 2020 daily mean visits and admissions decreased from 40.9 and 9.6 before lockdowns to $30.9(p<0.001)$ and $6.9(p=0.001)$ after severe restrictions, respectively. There was a trend towards more negative laboratory parameter profiles in 2020, with patients who visited the EDs after severe restrictions having twice as high median levels of C-reactive protein (15.39 vs. 7.84, $p=0.03$ ).

Conclusions: The observed declines in ED visits and admissions were apparent with the significant effect of national lockdowns. Our results indicate that some of the patients requiring urgent medical help did not appear at the ED or came later than they would have done before the pandemic, presenting with more severe complaints.

Key words: coronavirus, COVID-19, urology, emergency, admissions, visits.

\section{Introduction}

The pandemic of coronavirus disease 2019 (COVID-19) has had a tremendous impact on healthcare utilization worldwide, including drastically reduced patient care-seeking for medical emergencies unrelated to COVID-19. In China, Italy, the UK, and the US, initial reports suggest a decrease in visits to emergency departments (EDs) and admissions for urgent cardiac and neurological conditions [1-5]. In Italy and Portugal, there is also evidence of a decrease in ED visits and admissions for urgent urologic conditions but mostly reported in studies of a single center or a short duration [6-10].

Poland, a Central European country of 38 million people, had an initial peak of 475 COVID-19 cases on April 5, 2020 and saw its healthcare infrastructure generally less disrupted by the surge of COVID-19 cases than many other countries. However, in the early stage of the pandemic, because healthcare resources must be preserved and nosocomial and community transmission must be limited [11], the Polish National Health Fund (obligatory public insurance) and other major healthcare organizations recommended postponing routine and elective procedures [12, 13], and the Polish government introduced an initial national lockdown on March 14, 2020 and additional severe restrictions on March 25, 2020 [14, 15]. In detail, from March 14, 2020 shopping malls, sports centers, bars, cinemas, and libraries were closed. Public gatherings of 50 or more people were banned. The most severe restrictions (e.g., bans on non-essential movements outside the home and gatherings of more than two people) were applied from March 25, 2020. Nevertheless, many urgent urologic conditions, such as gross hematuria, urinary retention, and acute scrotum, require prompt interventions and if untreated can lead to serious morbidity and mortality. Patients with such conditions must seek care even during the COVID-19 era.
In this retrospective, multicenter, nationwide study, we aim to examine the change in the number and severity of visits to the ED and subsequent admissions for urgent urologic conditions in the early stage of the COVID-19 pandemic in Poland. We hypothesize that the number of visits to the ED and subsequent admissions decreased with increased severity of reported conditions.

\section{Material and methods}

In this retrospective, multicenter, nationwide study, we analyzed all emergency visits and admissions for urologic complaints at 13 urologic centers in Poland. All of the EDs in the study provided 24-hour urology service. We compared (1) the number of visits to the ED and subsequent admissions and (2) the laboratory patterns of urologic conditions for these visits and admissions before and after the advent of COVID-19 in 2020 and before and after the state of epidemic threat (initial national lockdown) in Poland on March 14, 2020, and after the most severe restrictions as implemented on March 25, 2020. The specific period of COVID-19 in this study was from February 29, 2020 to April 15, 2020 (2 weeks before to 1 month after the initial national lockdown); a preCOVID-19 reference period was selected as from February 28, 2019 to April 15, 2019 (Figure 1).

Due to heterogeneity in coding systems across institutions, we categorized urologic conditions into eight major groups by author consensus based on initial patient complaints, brief case descriptions, and reported the International Statistical Classification of Diseases and Related Health Problems, Tenth Revision (ICD-10) codes: renal colic, hematuria, urinary retention, urinary tract infection (UTI), device (urinary drainage tube) malfunction (e.g., nephrostomy tube dislocation, urinary catheter obstruction), acute scrotum, trauma, and others. We additionally collected patients' demographic and laboratory data, includ- 


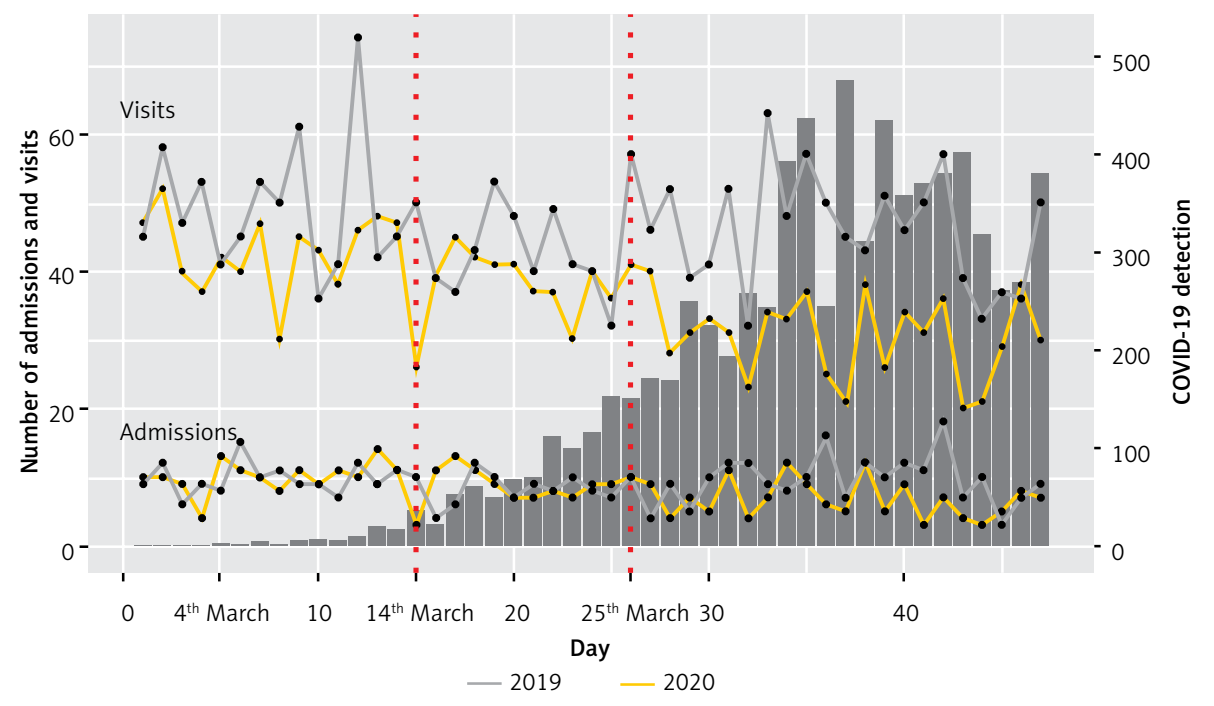

Figure 1. Emergency visits and admission in 2019 and 2020. Emergency visits and admissions due to all urological conditions in 2019 (grey) and 2020 (orange). Upper lines refers to visits, lower lines to admissions. In the background daily new COVID-19 cases in Poland. Day of introduction of the initial national lockdown (March 14, 2020) and more severe restrictions (March 25, 2020) are marked in red

ing C-reactive protein (CRP), hemoglobin ( $\mathrm{HGB}$ ), serum creatinine, and white blood count (WBC). Of note, because one center was transformed into a dedicated COVID-19 hospital on March 19, 2020, we censored data collected from this center $(n=81)$ up to March 18, 2019, and March 18, 2020 and did not include this center in analyzing the number of emergency visits and admissions before and after the lockdowns.

\section{Statistical analysis}

Continuous data are shown as median values with interquartile ranges (IQR) and categorical data are presented as absolute and relative frequencies (percentages), unless otherwise stated. Data were analyzed using nonparametric methods. Differences between two groups were determined using the Mann-Whitney $U$ test. Associations between categorical variables were assessed using the $\chi^{2}$ test. Two-sided $p$-values $<0.05$ were considered statistically significant. Analyses were carried out using $R$ software package version 4.0.1.

\section{Results}

In 47 days prior to April 15 at 13 urologic centers in Poland, we reported 1,696 ED visits for urological complaints in 2020, a $22.5 \%$ decrease from 2,187 in 2019, and 387 subsequent admissions in 2020, an $11.8 \%$ decrease from 439 in 2019. These changes corresponded to an increase in the admissions-to-ED-visits ratio from $20.1 \%$ in 2019 to $22.8 \%$ in 2020 ( $p=0.04$ ), as presented in Table I. The daily numbers of ED visits and admissions are depicted in Figure 1. Mean daily urology emer- gency visits decreased from 46.5 (95\% confidence interval (Cl): 44.0-49.1) visits in 2019 to 36.1 (95\% Cl: 33.8-38.4) visits in 2020 ( $p<0.001)$. There was also a non-significant decrease in mean admissions from 9.3 (95\% Cl: 8.5-10.2) in 2019 to 8.2 (95\% Cl: 7.4-9.1) in 2020 ( $p=0.13)$. Moreover, in 2020, a higher percentage of patients underwent urgent (within $24 \mathrm{~h}$ ) surgical intervention after admission (72.89\% vs. $81.14 \%, p=0.006)$. In the 1 month after the national lockdown (Table II), we reported 32.8 (95\% Cl: 30.5-35.1) daily mean ED visits for urological complaints and 7.5 (95\% Cl: 6.5-8.5) mean subsequent admissions, in comparison to 40.9 (95\% Cl: 37.6-44.3) and 9.6 (95\% Cl: 8.2-10.9), respectively, in the 2 weeks before the national lockdown $(p<0.001$ and $p=$ 0.014 , respectively). The declines were even greater after March 25, 2020 with daily mean visits and admissions decreasing to 30.9 (95\% Cl: 28.2-33.7) $(p<0.001)$ and $6.9(95 \% \mathrm{Cl}: 5.7-8.1)(p=0.007)$, respectively. Notably, despite a downtrend, no significant differences in visits or admissions were noticed before March 14, 2020 in comparison with the corresponding period (i.e., before March 14, 2019) (Table III). No significant differences in hospital length of stay were noted with a median of 4 days for all analyzed periods.

Urologic complaints reported at EDs were different between 2019 and 2020 (Table I). In our study, there was a year-over-year decrease in the absolute number of visits in renal colic (32\%), hematuria $(25 \%)$, urinary retention $(10 \%)$, acute scrotum (18\%), UTI (36\%), and trauma (7\%), but device malfunction, which increased by $66 \%$ (Table I). Also, consulted patients with device malfunction had higher median levels of creatinine: 
Table I. Clinical characteristics of the patients in 2019 and 2020

\begin{tabular}{|c|c|c|c|}
\hline Parameter & 2019 & 2020 & $P$-value \\
\hline Admissions/visits ratio & $20.10 \%$ & $22.80 \%$ & 0.038 \\
\hline Daily mean visits (SD) & $46.5(8.6)$ & $36.1(7.8)$ & $<0.001$ \\
\hline IRR $(95 \% \mathrm{Cl})$ visits & $0.78(0.73-0.83)$ & & \\
\hline Daily mean admissions (SD) & $9.3(2.9)$ & $8.2(2.9)$ & 0.13 \\
\hline IRR $(95 \% \mathrm{CI})$ admissions & $0.88(0.77-1.01)$ & & \\
\hline Age (visits) median (IQR) & $62(41-73)$ & $63(44-74)$ & 0.642 \\
\hline Sex (male) & $69.45 \%$ & $70,82 \%$ & 0.406 \\
\hline Diagnosis & & & 0.001 \\
\hline Renal colic & $658(34.31 \%)$ & $449(29.52 \%)$ & \\
\hline Hematuria & $306(15.95 \%)$ & $229(15.06 \%)$ & \\
\hline Urinary retention & $206(10.74 \%)$ & $186(12.23 \%)$ & \\
\hline Acute scrotum & $157(8.19 \%)$ & $128(8.42 \%)$ & \\
\hline UTI & $253(13.19 \%)$ & $163(10.72 \%)$ & \\
\hline Device malfunction & $119(6.20 \%)$ & $198(13.02 \%)$ & \\
\hline Trauma & $28(1.46 \%)$ & $26(1.71 \%)$ & \\
\hline Others & 191 (9.96\%) & $142(9.34 \%)$ & \\
\hline \multicolumn{4}{|l|}{ Laboratory parameters (visits): } \\
\hline $\mathrm{CRP}[\mathrm{ng} / \mathrm{ml}]$ & $10.00(2.09-56.83)$ & $11.19(2.00-86.46)$ & 0.171 \\
\hline $\mathrm{HGB}[\mathrm{g} / \mathrm{dl}]$ & $13.37(11.90-14.60)$ & $13.21(11.50-14.70)$ & 0.452 \\
\hline $\mathrm{WBC}[\mathrm{K} / \mu \mathrm{l}]$ & $10.08(7.70-13.30)$ & $10.30(8.12-13.50)$ & 0.161 \\
\hline $\mathrm{sCR}[\mu \mathrm{mol} / \mathrm{l}]$ & $91.50(75.14-123.76)$ & $94.59(73.37-126.85)$ & 0.526 \\
\hline \multicolumn{4}{|l|}{ Laboratory parameters (admissions): } \\
\hline CRP $[\mathrm{ng} / \mathrm{ml}]$ & $36.50(6.25-123.55)$ & $46.00(6.87-144.12)$ & 0.144 \\
\hline $\mathrm{HGB}[\mathrm{g} / \mathrm{dl}]$ & $12.60(11.00-13.86)$ & $12.41(10.63-14.10)$ & 0.608 \\
\hline $\mathrm{WBC}[\mathrm{K} / \mu \mathrm{l}]$ & $10.40(7.70-14.00)$ & $11.00(8.32-14.10)$ & 0.196 \\
\hline $\mathrm{sCR}[\mu \mathrm{mol} / \mathrm{l}]$ & $106.08(79.67-150.28)$ & $106.04(78.17-159.12)$ & 0.724 \\
\hline Urgent intervention after admission & $320(72.89 \%)$ & $314(81.14 \%)$ & 0.006 \\
\hline Type of intervention: & & & 0.866 \\
\hline Endoscopic & $185(57.81 \%)$ & $170(53.50 \%)$ & \\
\hline Open & $39(12.19 \%)$ & $46(14.65 \%)$ & \\
\hline Percutaneous & $85(26.56 \%)$ & $94(29.62 \%)$ & \\
\hline Others & $9(2.81 \%)$ & $6(1.91 \%)$ & \\
\hline Hospitalization [days] & $4.00(2.00-7.00)$ & $4.00(2.00-7.00)$ & 0.283 \\
\hline
\end{tabular}

Continuous variables are presented as median (interquartile range). Dichotomous variables are presented as percentages. $\mathrm{Cl}-\mathrm{confidence}$ interval, $C R P$ - C-reactive protein, $H G B$ - hemoglobin, IRR - incidence rate ratio, IQR - interquartile range, $S C R-s e r u m$ creatinine, $S D$ - standard deviation, UTI - urinary tract infection, WBC - white blood count. 
P. Rajwa, M. Przydacz, W. Krajewski, B. Kuffel, P. Zapala, A. Krzywon, A.J. Cortez, B. Dybowski, R. Stamirowski, M. Jarzemski, R.B. Drobot, P. Stelmach, K. Mlynarek, M. Marcinek, M. Przudzik, W. Krawczyk, J. Ryszawy, D. Choragwicki, L. Zapala, M. Lipa, M. Pozniak, D. Janczak, S. Stomian, J. Łaszkiewicz, M. Nowak, M. Miszczyk, M. Roslan, M. Tkocz, R. Zdrojowy, A. Potyka, T. Szydełko, T. Drewa, P. Jarzemski,

P. Radziszewski, M. Slojewski, A. Antoniewicz, A. Paradysz, P.L. Chlosta

Table II. Clinical characteristics of the patients before lockdowns, after March $14^{\text {th }} 2020$ and after March $25^{\text {th }}, 2020$

\begin{tabular}{|c|c|c|c|c|c|}
\hline Parameter & $\begin{array}{l}\text { Before March 14, } \\
\qquad 2020\end{array}$ & After March 14, 2020 & $P$-value* & After March 25, 2020 & $P$-value* \\
\hline Admissions/visits ratio & $23.40 \%$ & $22.70 \%$ & 0.76 & $22.35 \%$ & 0.66 \\
\hline Daily mean visits (SD) & $40.9(5.8)$ & $32.8(6.5)$ & $<0.001$ & $30.9(6.3)$ & $<0.001$ \\
\hline $\begin{array}{l}\text { IRR }(95 \% \mathrm{Cl}) \text { visits after } \\
\text { March } 14,2020\end{array}$ & $0.8(0.73-0.89)$ & & & & \\
\hline $\begin{array}{l}\text { IRR }(95 \% \mathrm{CI}) \text { visits after } \\
\text { March } 25,2020\end{array}$ & $0.76(0.68-0.84)$ & & & & \\
\hline Daily mean admissions (SD) & $9.6(2.3)$ & $7.5(2.8)$ & 0.014 & $6.9(2.8)$ & 0.007 \\
\hline $\begin{array}{l}\text { IRR }(95 \% \mathrm{Cl}) \text { admissions } \\
\text { after March 14, } 2020\end{array}$ & $0.78(0.63-0.96)$ & & & & \\
\hline $\begin{array}{l}\text { IRR }(95 \% \mathrm{Cl}) \text { admissions } \\
\text { after March 25, } 2020\end{array}$ & $0.72(0.57-0.91)$ & & & & \\
\hline Age (visits) & $63(44.00-73.00)$ & $63(44.00-75.00)$ & 0.199 & $64(45.00-75.00)$ & 0.201 \\
\hline Sex (male) & $67.20 \%$ & $72.54 \%$ & 0.038 & $72.28 \%$ & 0.076 \\
\hline Diagnosis & & & 0.110 & & 0.025 \\
\hline Renal colic & $167(33.00 \%)$ & $275(28.21 \%)$ & & $159(25.94 \%)$ & \\
\hline Hematuria & $82(16.21 \%)$ & $139(14.26 \%)$ & & $84(13.70 \%)$ & \\
\hline Urinary retention & $53(10.47 \%)$ & $127(13.03 \%)$ & & $82(13.38 \%)$ & \\
\hline Acute scrotum & $39(7.71 \%)$ & $82(8.41 \%)$ & & $53(8.65 \%)$ & \\
\hline UTI & $51(10.08 \%)$ & $109(11.18 \%)$ & & $77(12.56 \%)$ & \\
\hline Device malfunction & $52(10.28 \%)$ & $141(14.46 \%)$ & & $94(15.33 \%)$ & \\
\hline Trauma & $11(2.17 \%)$ & $14(1.44 \%)$ & & $10(1.63 \%)$ & \\
\hline Others & $51(10.08 \%)$ & $88(9.03 \%)$ & & $54(8.81 \%)$ & \\
\hline \multicolumn{6}{|l|}{$\begin{array}{l}\text { Laboratory parameters } \\
\text { (visits): }\end{array}$} \\
\hline $\mathrm{CRP}[\mathrm{ng} / \mathrm{ml}]$ & $7.84(1.42-83.98)$ & $13.00(2.12-88.30)$ & 0.059 & 15.39 (2.17-91.70) & 0.032 \\
\hline $\mathrm{HGB}[\mathrm{g} / \mathrm{dl}]$ & $13.21(11.60-14.73)$ & $13.21(11.40-14.65)$ & 0.886 & $13.30(11.40-14.70)$ & 0.753 \\
\hline WBC $[K / \mu l]$ & $10.05(8.30-13.05)$ & $10.39(8.09-13.68)$ & 0.291 & $10.67(8.27-13.83)$ & 0.247 \\
\hline $\mathrm{sCR}[\mu \mathrm{mol} / \mathrm{l}]$ & $96.00(76.91-127.96)$ & $91.60(72.49-128.05)$ & 0.799 & $90.17(72.49-130.83)$ & 0.288 \\
\hline \multicolumn{6}{|l|}{$\begin{array}{l}\text { Laboratory parameters } \\
\text { (admissions): }\end{array}$} \\
\hline CRP $[\mathrm{ng} / \mathrm{ml}]$ & 45.03 (3.10-137.23) & $58.24(10.60-150.00)$ & 0.103 & 59.97 (13.14-150.00) & 0.099 \\
\hline $\mathrm{HGB}[\mathrm{g} / \mathrm{dl}]$ & $12.50(10.31-14.10)$ & $12.40(10.80-14.12)$ & 0.696 & $12.50(11.00-14.40)$ & 0.320 \\
\hline $\mathrm{WBC}[\mathrm{K} / \mu \mathrm{l}]$ & $11.00(8.00-14.30)$ & $11.06(8.49-14.06)$ & 0.805 & $11.23(8.44-14.10)$ & 0.199 \\
\hline $\mathrm{sCR}[\mu \mathrm{mol} / \mathrm{l}]$ & $108.73(79.56-181.22)$ & $102.00(77.13-148.29)$ & 0.280 & $99.89(73.37-150.28)$ & 0.777 \\
\hline $\begin{array}{l}\text { Urgent intervention after } \\
\text { admission }\end{array}$ & $112(79.43 \%)$ & $202(82.11 \%)$ & 0.607 & $128(84.21 \%)$ & 0.335 \\
\hline Type of intervention: & & & 0.627 & & 0.787 \\
\hline Endoscopic & $62(55.36 \%)$ & $106(52.48 \%)$ & & $65(50.78 \%)$ & \\
\hline Open & 19 (16.96\%) & $27(13.37 \%)$ & & $20(15.63 \%)$ & \\
\hline Percutaneous & $28(25.00 \%)$ & 65 (32.18\%) & & $40(31.25 \%)$ & \\
\hline Others & $3(2.68 \%)$ & $3(1.49 \%)$ & & $3(2.34 \%)$ & \\
\hline Hospitalization [days] & $4.00(2.00-7.00)$ & $4.00(2.00-7.00)$ & 0.508 & $4.00(2.00-7.00)$ & 0.344 \\
\hline
\end{tabular}

${ }^{*}$ Compared to the pre-March 14, 2020 period. Continuous variables are presented as median (interquartile range). Dichotomous variables are presented as percentages. $C I$ - confidence interval, $C R P-C$-reactive protein, $H G B$ - hemoglobin, IRR - incidence rate ratio, $I Q R$ - interquartile range, $S C R$ - serum creatinine, SD - standard deviation, UTI - urinary tract infection, WBC - white blood count. 
Table III. Comparisons of visits and admissions in 2019 vs. 2020 in periods before March 14 ${ }^{\text {th }}$ (A), periods from March $14^{\text {th }}(B)$, periods from March $25^{\text {th }}($ C $)$

A

\begin{tabular}{|c|c|c|c|}
\hline Parameter & $28.02-13.03 .2019$ & $29.02-13.03 .2020$ & $P$-value \\
\hline Daily mean visits & 47.1 & 40.9 & 0.1 \\
\hline IRR (95\% CI) & $0.87(0.78-0.97)$ & & \\
\hline Daily mean admissions & 9.6 & 9.6 & 0.91 \\
\hline IRR $(95 \% \mathrm{Cl})$ & $0.99(0.78-1.26)$ & & \\
\hline
\end{tabular}

B

\begin{tabular}{|lccc|}
\hline Parameter & $\mathbf{1 4 . 0 3 - 1 5 . 0 4 . 2 0 1 9}$ & $\mathbf{1 4 . 0 3 - 1 5 . 0 4 . 2 0 2 0}$ & $P$-value \\
\hline Daily mean visits & 45 & 32.8 & $<.001$ \\
\hline IRR $(95 \% \mathrm{Cl})$ & $0.73(0.68-0.79)$ & & 0.037 \\
\hline Daily mean admissions & 9.1 & & 7.5 \\
\hline IRR $(95 \% \mathrm{Cl})$ & $0.82(0.69-0.97)$ & & \\
\hline
\end{tabular}

C

\begin{tabular}{|c|c|c|c|}
\hline Parameter & $25.03-15.04 .2019$ & $25.03-15.04 .2020$ & $P$-value \\
\hline Daily mean visits & 46.5 & 30.9 & $<0.001$ \\
\hline $\operatorname{IRR}(95 \% \mathrm{CI})$ & $0.66(0.6-0.73)$ & & \\
\hline Daily mean admissions & 9.6 & 6.9 & 0.001 \\
\hline IRR $(95 \% \mathrm{CI})$ & $0.72(0.58-0.89)$ & & \\
\hline
\end{tabular}

141.44 (IQR: $98.00-262.33)$ in 2020 vs. 108.87 (IQR: 86.00-134.03) in $2019(p=0.04)$ and higher levels of WBC: 12.47 (IQR: 9.80-15.08) in 2020 vs. 8.92 (IQR: 7.30-12.25) in 2019 ( $p=0.005)$, as presented in Table IV. Furthermore, in patients with UTI, the median CRP level was 117.50 (IQR: 28.84234.12) in 2020 and 79.67 (IQR: 16.00-180.30) in $2019(p=0.01)$. No significant differences between 2019 and 2020 were found in laboratory parameters in all patients visiting and admitted to urology departments, although there was a trend towards worse parameter profiles in 2020 patients (Table I).

Finally, patients visiting the EDs after the lockdowns (Table II) had a higher level of CRP: 7.84 (IQR: 1.42-83.98) before, 13.00 (IQR: 2.12-88.30) after the initial lockdown $(p=0.06)$, and 15.39 (IQR: 2.17-91.70) after the introduction of severe restrictions $(p=0.03)$. Importantly, patients admitted after the initial lockdown for renal colic had a significantly higher level of CRP - 32.60 (IQR: 6.75-97.00) compared to patients admitted before the lockdown - 7.77 (IQR: 1.30-83.37) $(p=0.02)$ (Table V). After the initial lockdown patients consulted due to hematuria had due to hematuria had borderline significantly lower median HGB levels - 11.60 (IQR: 10.10-13.65) compared to patients visiting before the initial lockdown 12.70 (IQR: 10.90-14.40) $(p=0.05)$.

\section{Discussion}

In this study, we report a $22.5 \%$ year-overyear decrease in the number of visits to the EDs for urgent urologic conditions after the advent of COVID-19 but a 2.7 percentage points (p.p.) yearover-year increase in the number of the admissions-to-ED-visit ratio. Also, in 2020 there were $20 \%$ and $24 \%$ decreases in the number of visits to the ED and $22 \%$ and $28 \%$ decreases in the number of subsequent admissions for urgent urologic conditions after the initial lockdown and after further severe restrictions, respectively. Considering laboratory parameters, there was a trend towards more negative laboratory parameter profiles in 2020, and patients who visited the EDs after implementation of the most severe restrictions had almost twice as high median levels of CRP. Furthermore, in 2020 there was an 8 p.p. increase in patients requiring surgical intervention within $24 \mathrm{~h}$ after admission.

To our knowledge, we present the largest, multi-center, nationwide study delineating urologic ED visits and urgent admissions during the COVID-19 era, with the subsequent impact of escalating national lockdowns. Furthermore, our study is the first one that has directly aimed to examine the impact of the pandemic on patients 
P. Rajwa, M. Przydacz, W. Krajewski, B. Kuffel, P. Zapala, A. Krzywon, A.J. Cortez, B. Dybowski, R. Stamirowski, M. Jarzemski, R.B. Drobot, P. Stelmach, K. Mlynarek, M. Marcinek, M. Przudzik, W. Krawczyk, J. Ryszawy, D. Choragwicki, L. Zapala, M. Lipa, M. Pozniak, D. Janczak, S. Stomian, J. Łaszkiewicz, M. Nowak, M. Miszczyk, M. Roslan, M. Tkocz, R. Zdrojowy, A. Potyka, T. Szydełko, T. Drewa, P. Jarzemski,

P. Radziszewski, M. Slojewski, A. Antoniewicz, A. Paradysz, P.L. Chlosta

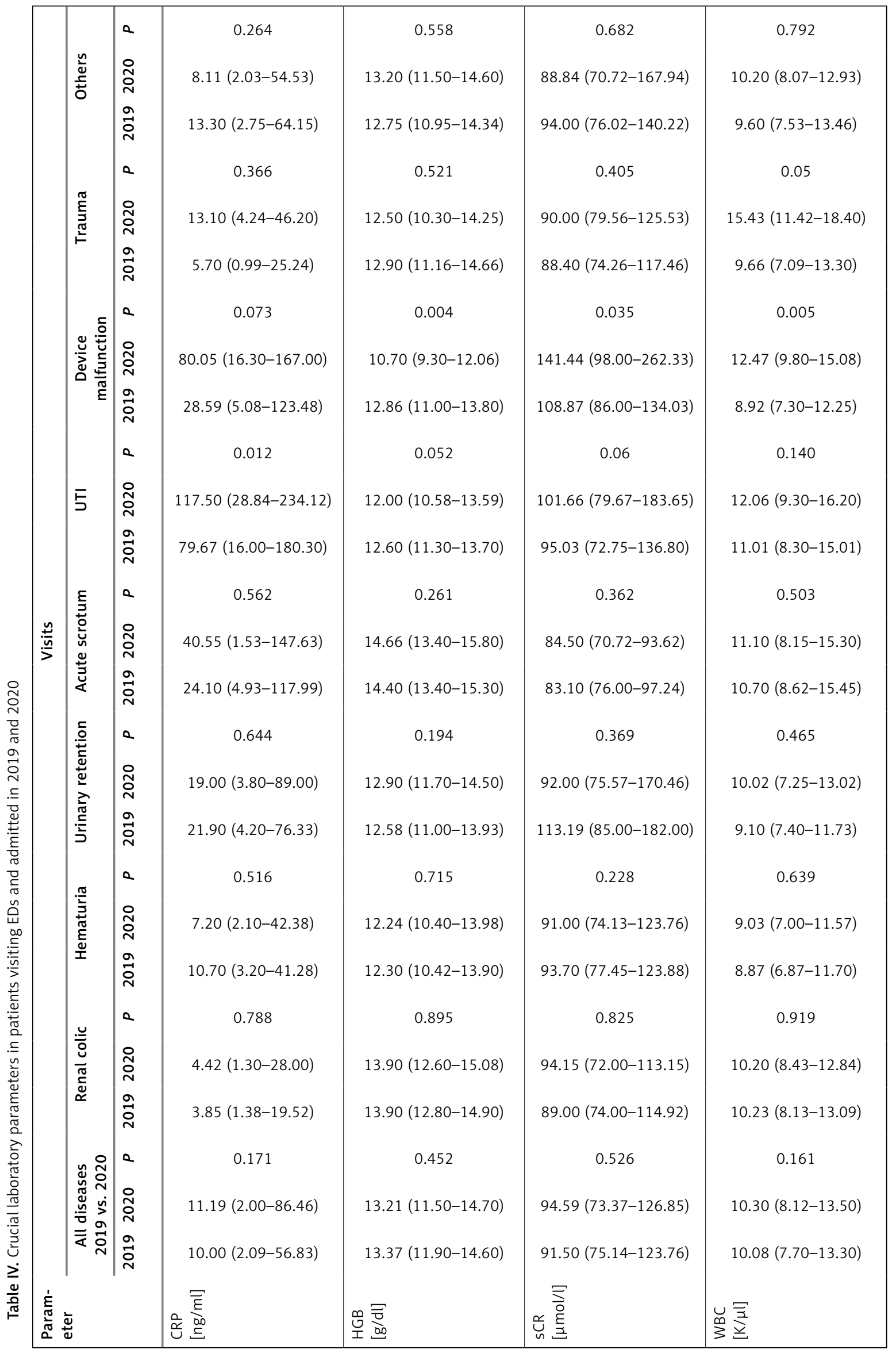


Changing patterns of urologic emergency visits and admissions during the COVID-19 pandemic: a retrospective, multicenter, nationwide study

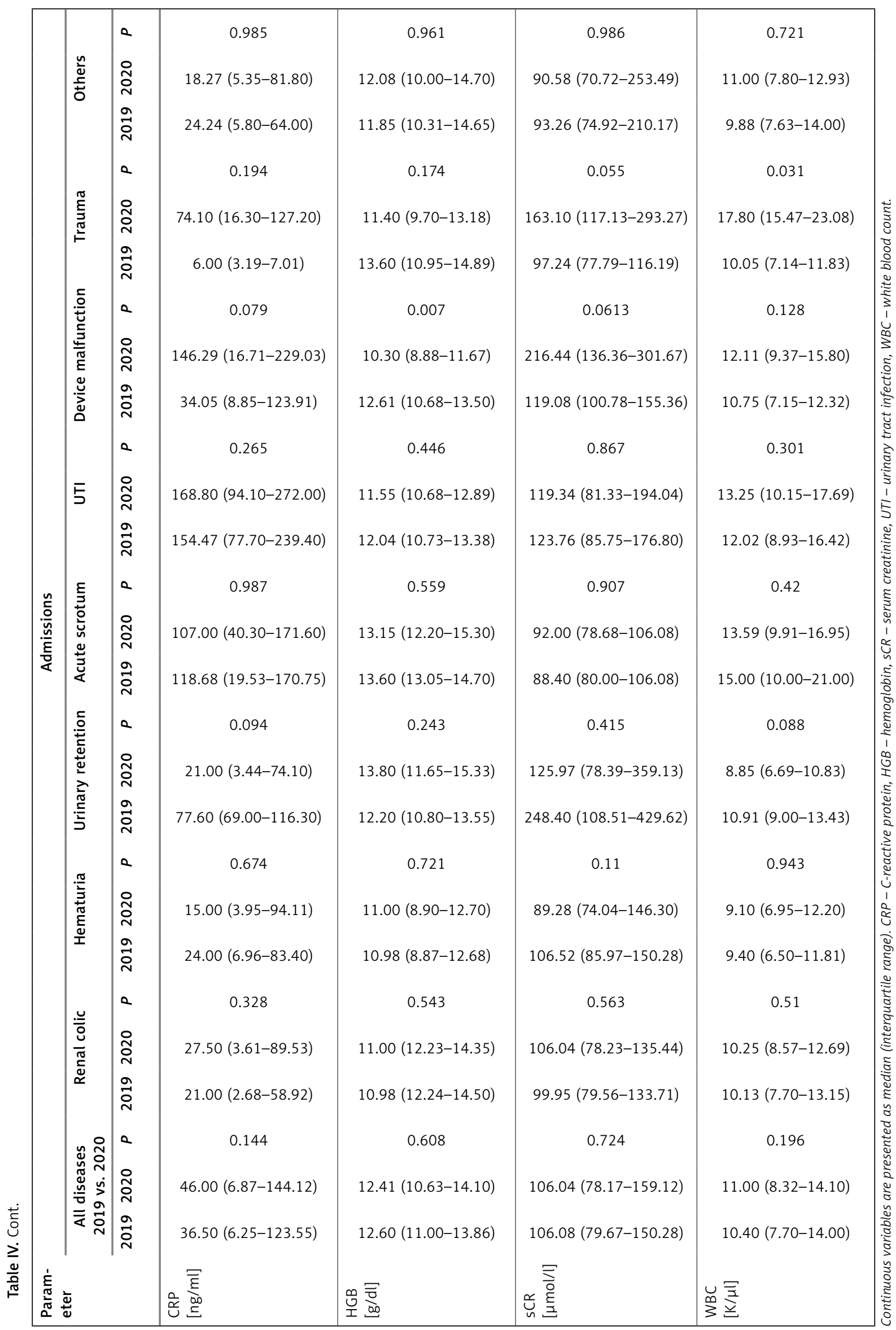


P. Rajwa, M. Przydacz, W. Krajewski, B. Kuffel, P. Zapala, A. Krzywon, A.J. Cortez, B. Dybowski, R. Stamirowski, M. Jarzemski, R.B. Drobot, P. Stelmach, K. Mlynarek, M. Marcinek, M. Przudzik, W. Krawczyk, J. Ryszawy, D. Choragwicki, L. Zapala, M. Lipa, M. Pozniak, D. Janczak, S. Słomian, J. Łaszkiewicz, M. Nowak, M. Miszczyk, M. Roslan, M. Tkocz, R. Zdrojowy, A. Potyka, T. Szydełko, T. Drewa, P. Jarzemski,

P. Radziszewski, M. Slojewski, A. Antoniewicz, A. Paradysz, P.L. Chlosta

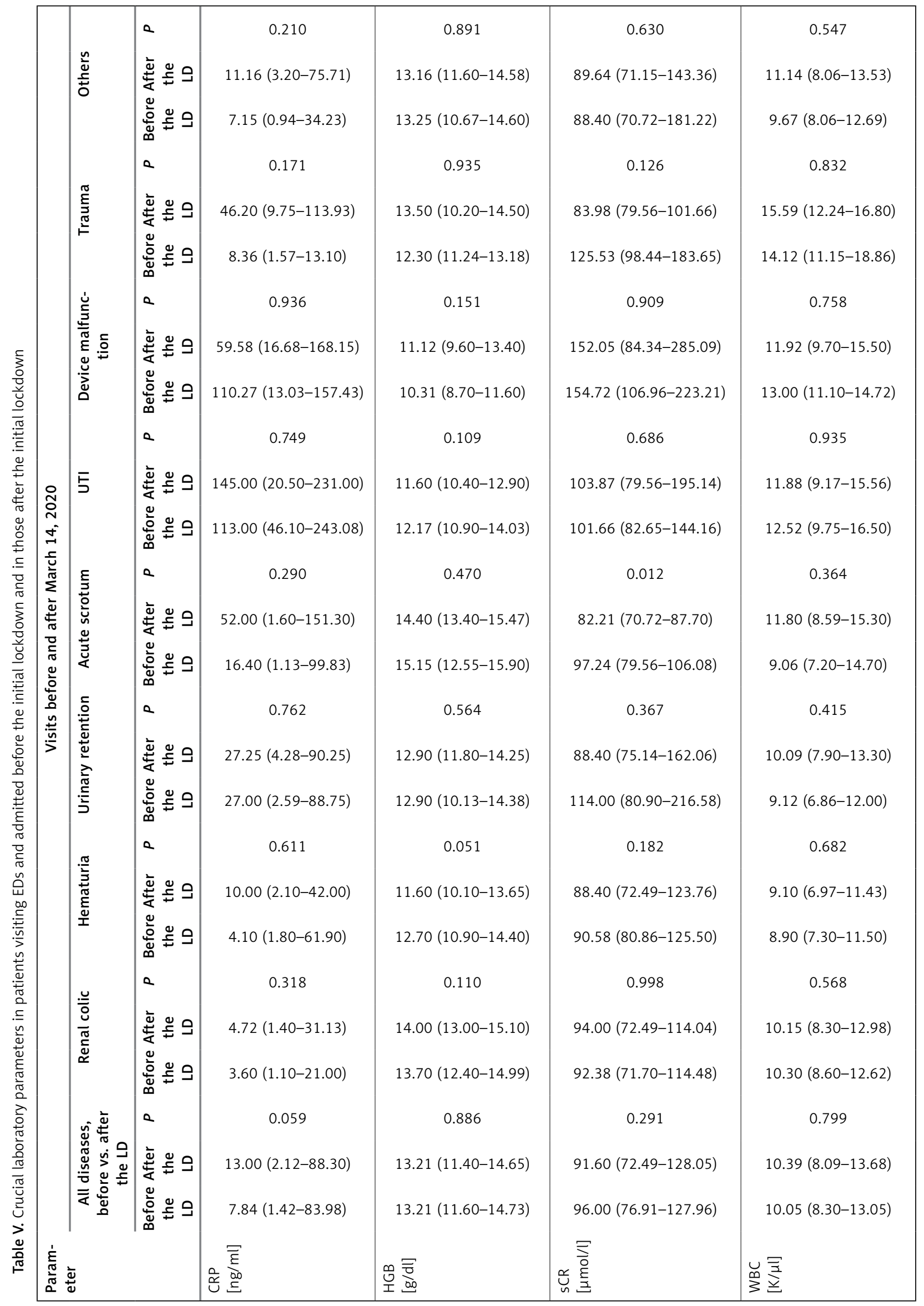




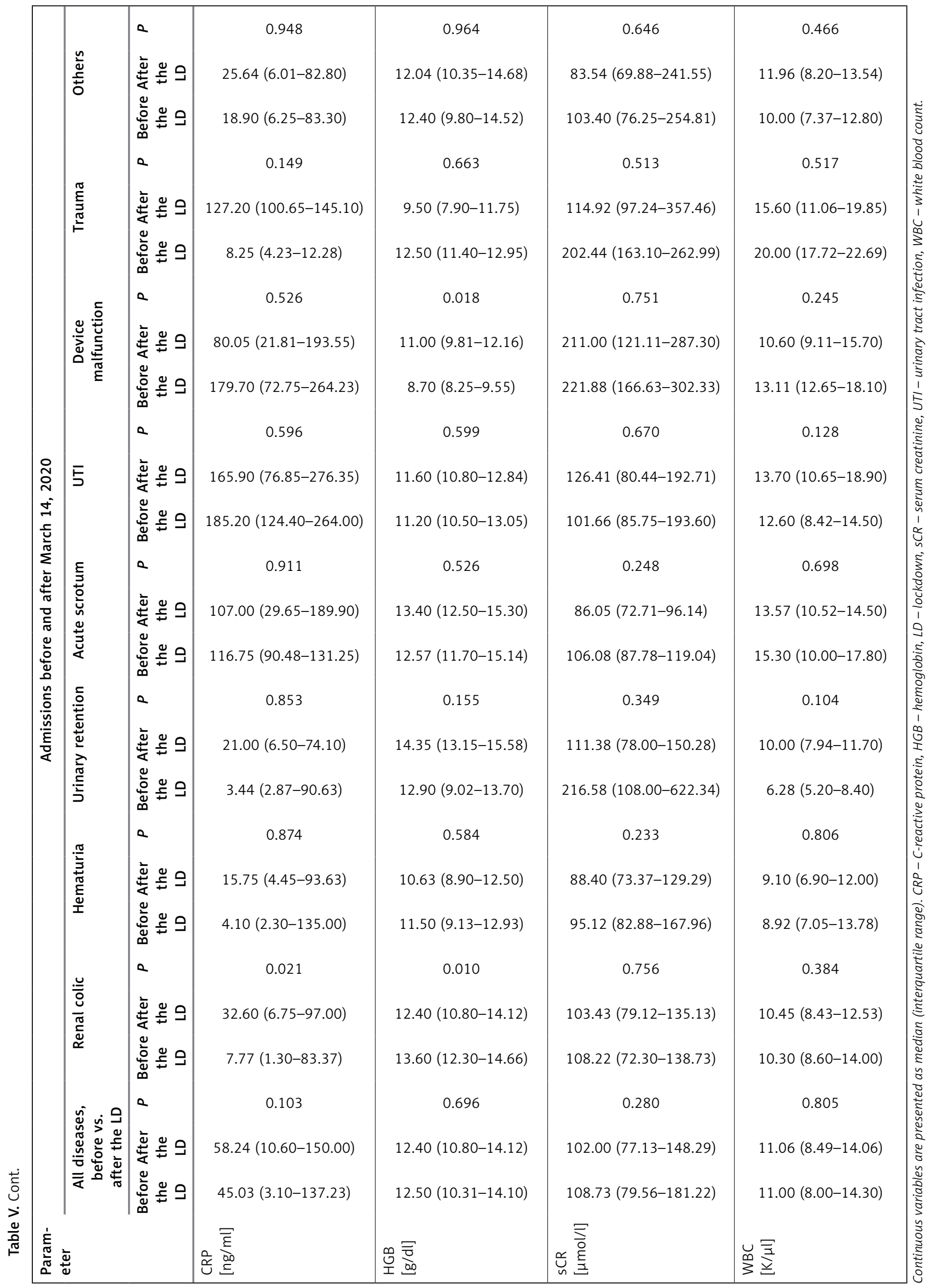


complaining about all urologic conditions by analyses of daily mean visits and admissions, crucial laboratory parameters, post-admission procedures, and hospital length of stay.

Our analyses revealed lower $(22.5 \%)$ year-overyear decreases in urologic ED visits, compared to recently published Italian and Portuguese studies, which found over $50 \%$ declines during the COVID-19 period [7-10]. In Poland, the changes were slightly more comparable to more affected countries after the introduction of more severe restrictions on March 25, 2020, with declines up to $34 \%$ (Table III). This has been also seen in another Polish study of Legutko et al., who evaluated pre-COVID-19 and COVID-19 periods (all 2020) in terms of coronary angiography and percutaneous coronary interventions for myocardial infarctions. The authors also found smaller decreases in emergency cases after the lockdown (30\%) when compared to the US (38\%), Spain (40\%), or Austria (39\%) [4]. There are several possible explanations for smaller declines in Poland. From the end of February, following massive outbreaks in Italy, France, Spain, and Germany, in Poland the fear and expectance of a COVID-19 outbreak were present. As the first expected COVID-19 case in Poland (March 4, 2020), with subsequent logarithmic case growth, appeared later (Figure 1) when compared to the abovementioned countries, early precautions were taken, leading to a lower, stable COVID-19 incidence ratio, more smoothly manageable for healthcare [16]. Therefore, we speculate that Poland serves as an example of a country where the possible changes in emergency visits and admissions were not due to impaired access to emergency health care but were mainly related to the escalating restrictions (including isolations and limited access to urologic and other specialization outpatient services) followed by fear or patients' perception of hospitals as COVID-19 reservoirs $[17,18]$. Further, as fewer doctors in Poland, compared to countries more affected by COVID-19, were directly engaged in managing COVID-19 patients, greater availability and unparalleled popularity of telemedicine consultations could have led to fewer urgent and sometimes unnecessary visits. Finally, cultural differences, media coverage, and population fear level, which varies significantly among nations (e.g. lower COVID-19 fear level in Eastern Europeans), may also have played a role in our lower declines in ED attendance [19-21].

In 2020, problems with device malfunctions increased by $66 \%$, while all other groups of urologic problems subsided. The distribution of diseases was significantly different between 2019 and $2020(p=0.001)$, which was also noted in a study of Novara et al. $(n=399)$, although in their cohort declines were seen in all disease groups $(p=0.04)$
[9]. Conversely, in another study from Porto, Portugal $(n=385)$, a higher proportion of patients visited the ED for administrative and clinical reasons and due to device malfunctions ( $n=12$ (9.8\%) in 2020 and 15 (5.7\%) in 2019) [8]. These results can be related to ours, as more patients with device malfunction were noted in EDs, presumably due to limited access to regular outpatient care.

The initial reports from outbreak regions indicate higher general mortality, which cannot be directly linked to COVID-19 deaths [1, 18, 22]. As mortality rates in urologic emergencies are relatively very low, we believe crucial laboratory parameters could substantiate the patients' condition. In our cohort, there were no significant differences between tested laboratory parameters between 2019 and 2020, in either consulted or admitted patients, although a clear more negative tendency was noticed. Requiring particular attention are the higher levels of creatinine, CRP, and WBC in the device malfunction group in 2020, which were either significant or borderline significant for both consulted and admitted patients. In 2020 patients visiting EDs due to UTI had significantly higher levels of CRP. After the lockdowns, compared to the pre-lockdown period, all the visiting patients had approximately twice as high median CRP level and patients consulted due to hematuria had borderline significantly lower HGB levels. All these results may somewhat mirror the delayed care-seeking in 2020 and ED avoidance in milder cases. The only study that evaluated laboratory parameters during the COVID-19 pandemic in urologic emergencies, particularly in renal colic patients $(n=80)$, was conducted by Flammia et al. [10]. Surprisingly, the patients visiting during the COVID-19 era had non-significantly lower WBC levels $(p=0.052)$, but significantly higher serum creatinine levels $(p=0.026)$, which we did not observe in our cohort. Nevertheless, after lockdowns, we found significantly higher median levels of CRP in admitted renal colic patients (Tables $\mathrm{V}$ and $\mathrm{VI}$ ).

The admissions-to-ED-visit ratio was significantly higher in 2020 compared to 2019, which indicates that presumably in general more "mild" visits were avoided in 2020. On the other hand, in 2020 a higher percentage of admitted patients underwent urgent intervention after admission with general stable absolute numbers of operations between 2019 and 2020, which could indicate a more severe condition of admitted patients. No differences in hospitalization time were noted, which could also be due to a general tendency to shorten patients' hospital length of stay during the COVID-19 pandemic, as also observed in other countries [19]. In a study conducted by the Italian AGILE group, there was an over $50 \%$ decline in the ureterorenoscopy (and/ 
Changing patterns of urologic emergency visits and admissions during the COVID-19 pandemic: a retrospective, multicenter,
nationwide study

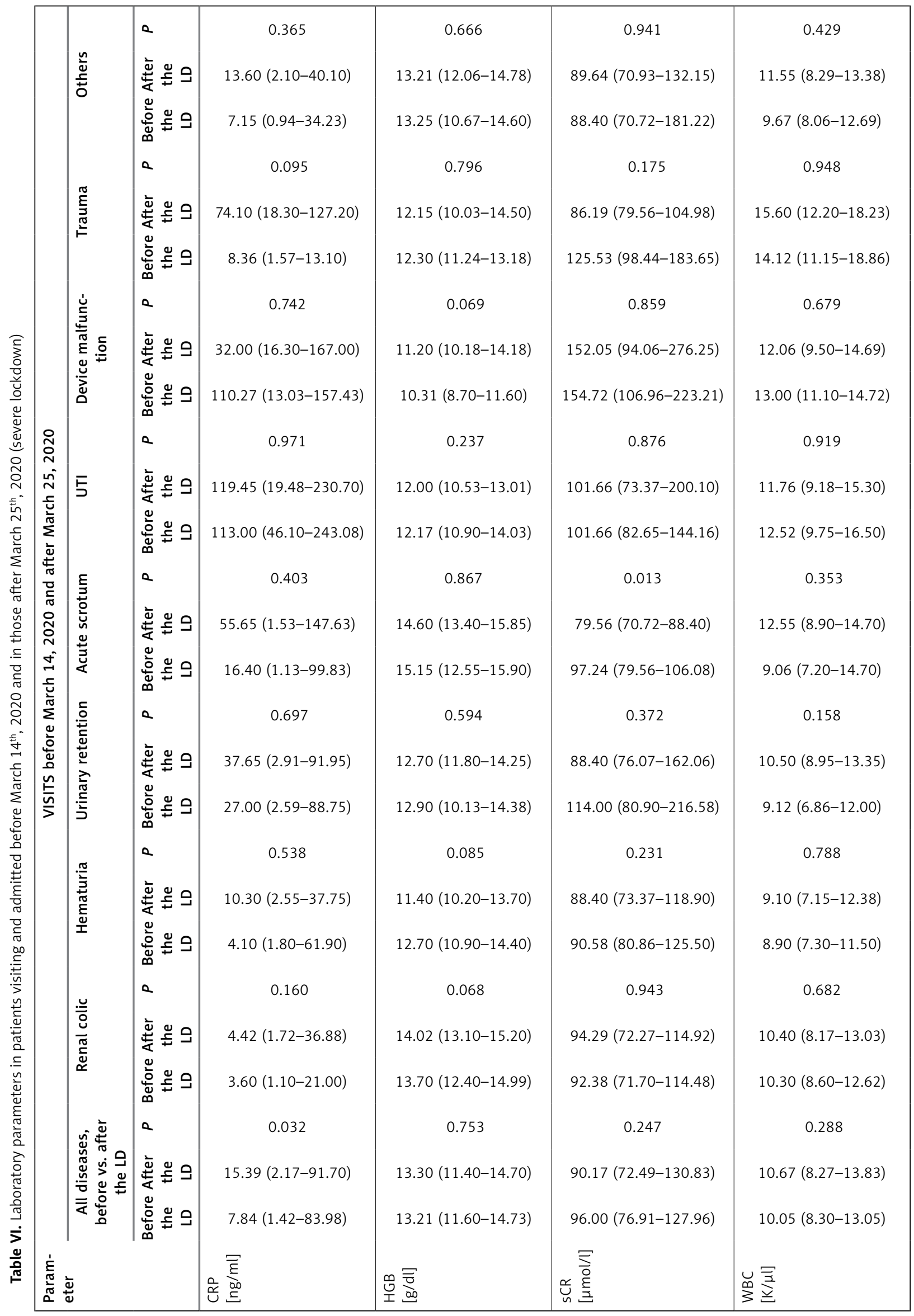


P. Rajwa, M. Przydacz, W. Krajewski, B. Kuffel, P. Zapala, A. Krzywon, A.J. Cortez, B. Dybowski, R. Stamirowski, M. Jarzemski, R.B. Drobot, P. Stelmach, K. Mlynarek, M. Marcinek, M. Przudzik, W. Krawczyk, J. Ryszawy, D. Choragwicki, L. Zapala, M. Lipa, M. Pozniak, D. Janczak, S. Słomian, J. Łaszkiewicz, M. Nowak, M. Miszczyk, M. Roslan, M. Tkocz, R. Zdrojowy, A. Potyka, T. Szydełko, T. Drewa, P. Jarzemski,

P. Radziszewski, M. Slojewski, A. Antoniewicz, A. Paradysz, P.L. Chlosta

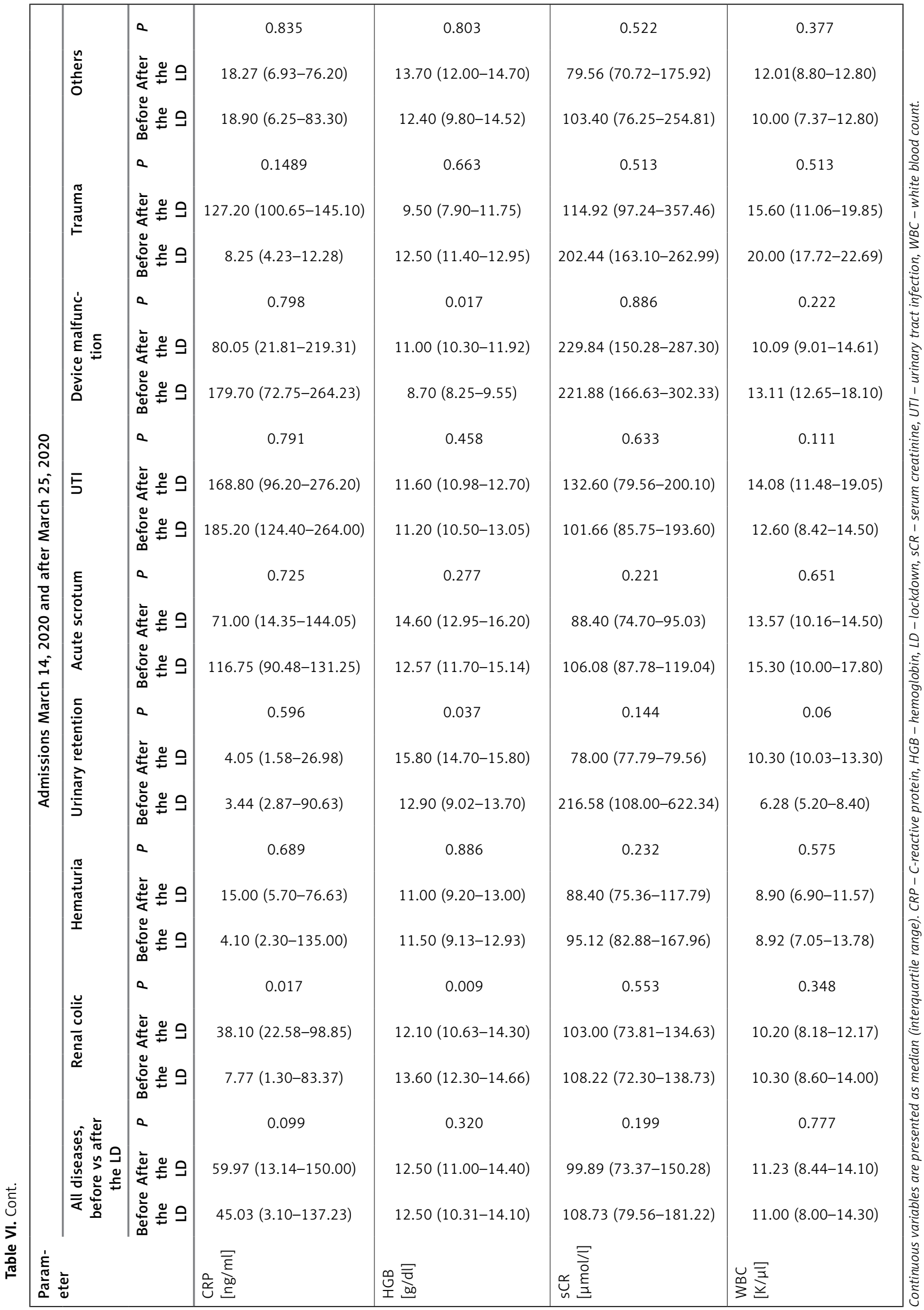


or ureteral stenting), transurethral resection of bladder tumor, and testicular detorsion between a pre-COVID period in 2020 and during the massive outbreak in Italy [6]. In our cohort, the distribution of the interventions was non-significantly different with an $8 \%$ decrease in absolute numbers of endoscopic procedures in 2020. At the same time, we noted a higher number of open and percutaneous interventions in 2020 and a higher proportion of percutaneous interventions after the lockdowns.

Our results illustrate a distressing tendency that some of the patients who truly needed urgent medical help and/or hospitalization were not seen at urologic EDs or came later than they would have done before the COVID-19 era. In our opinion, the Polish case may arise in other developed countries, after the pandemic stabilizes and in a case of local outbreaks with maintained access to urologic EDs. Lastly, our paper underlines the necessity for adjustment of urology centers during the COVID-19 pandemic. Primarily, despite the unprecedented integration of telemedicine in outpatient clinics, more meticulous patients' qualifications for in-person visits should be implemented. Given the presumable scenario with the COVID-19 pandemic lasting for an unknown period, maintaining regular face-to-face access for needy patients should become a critical aim of health care providers. Additionally, we believe that broader and easily available information provision concerning current epidemiological status should be immediately implemented to both EDs and outpatient service, which could partly mitigate patients' fear and uncertainty.

There are some limitations of our study. Firstly, this is a time-limited, retrospective, single-country study. However, the majority of our 13 study centers have high-volume urology departments, thus providing a robust national sample. Second, there were missing demographic, ICD-10 and laboratory data on ED visits at one center and some missing laboratory data due to a lack of clinical indication. Lastly, we did not control for confounding factors that might have influenced laboratory results in our analyses.

In conclusion, our study compiled several important and exclusive aspects of urology ED visits and admissions during the COVID-19 pandemic, in a country with barely impaired access to emergency medicine. Declines in urologic emergency visits and admissions were apparent, especially after the introduction of restrictions, with alarming trends indicating that some of the patients requiring urgent medical help did not appear at the ED, or came later than they would have done before the pandemic, presenting worse laboratory profiles.

\section{Acknowledgments}

AJC is supported by the European Union through the European Social Fund (POWR.03.02.00-001029).

\section{Conflict of interest}

The authors declare no conflict of interest.

\section{References}

1. De Filippo O, D'Ascenzo F, Angelini F, et al. Reduced rate of hospital admissions for ACS during Covid-19 outbreak in Northern Italy. N Engl J Med 2020; 383: 88-9.

2. Thornton J. Stroke: "striking reductions" are seen in number of people with symptoms seeking help. BMJ 2020; 369: m1406.

3. Tam CF, Cheung KS, Lam S, et al. Impact of coronavirus disease 2019 (COVID-19) outbreak on outcome of myocardial infarction in Hong Kong, China. Catheter Cardiovasc Interv 2020; 13: e006631.

4. Legutko J, Niewiara $Ł$, Bartuś S, et al. The decline of coronary angiography and percutaneous coronary intervention procedures in patients with acute myocardial infarction in Poland during the COVID-19 pandemic. LID - 10.33963/KP.15393 [doi] FAU - Legutko, Jacek. (18974279 (Electronic)).

5. Baum A, Schwartz MD. Admissions to veterans affairs hospitals for emergency conditions during the COVID-19 pandemic. JAMA 2020; 324: 96-9.

6. Porreca A, Colicchia M, D'Agostino D, et al. Urology in the time of coronavirus: reduced access to urgent and emergent urological care during the coronavirus disease 2019 outbreak in Italy. Urol Int 2020; 104: 7-8.

7. Motterle G, Morlacco A, lafrate $M$, et al. The impact of COVID-19 pandemic on urological emergencies: a single-center experience. World J Urol 2020: 1-5. doi: 10.1007/s00345-020-03264-2.

8. Madanelo M, Ferreira C, Nunes-Carneiro D, et al. The impact of the COVID-19 pandemic on the utilization of emergency urological services. BJU Int 2020; 126: 256-8.

9. Novara G, Bartoletti R, Crestani A, et al. Impact of COVID-19 pandemic on the urologic practice in the emergency departments in Italy. BJU Int 2020; 126: 245-7.

10. Flammia S, Salciccia S, Tufano A, Busetto GM, Ricciuti GP, Sciarra A. How urinary stone emergencies changed in the time of COVID-19? Urolithiasis 2020; 48: 467-9.

11. Black JRM, Bailey C, Przewrocka J, Dijkstra KK, Swanton C. COVID-19: the case for health-care worker screening to prevent hospital transmission. Lancet 2020; 395: 1418-20.

12. Stensland KD, Morgan TM, Moinzadeh A, et al. Considerations in the triage of urologic surgeries during the COVID-19 pandemic. Eur Urol 2020; 77: 663-6.

13. Teoh JY, Ong WLK, Gonzalez-Padilla D, et al. A global survey on the Impact of COVID-19 on urological services. Eur Urol 2020: 78: 265-75.

14. Rozporządzenie Ministra Zdrowia. 13 ${ }^{\text {th }}$ March 2020. [http://prawo.sejm.gov.pl/isap.nsf/DocDetails.xsp?id =WDU20200000433]

15. Rozporządzenie Ministra Zdrowia. 24 ${ }^{\text {th }}$ marca 2020. [http://prawo.sejm.gov.pl/isap.nsf/DocDetails.xsp?id= WDU20200000433]

16. Gujski M, Raciborski F, Jankowski M, Nowicka PM, Rakocy K, Pinkas J. Epidemiological analysis of the first 1389 
P. Rajwa, M. Przydacz, W. Krajewski, B. Kuffel, P. Zapala, A. Krzywon, A.J. Cortez, B. Dybowski, R. Stamirowski, M. Jarzemski, R.B. Drobot, P. Stelmach, K. Mlynarek, M. Marcinek, M. Przudzik, W. Krawczyk, J. Ryszawy, D. Choragwicki, L. Zapala, M. Lipa, M. Pozniak, D. Janczak, S. Stomian, J. Łaszkiewicz, M. Nowak, M. Miszczyk, M. Roslan, M. Tkocz, R. Zdrojowy, A. Potyka, T. Szydełko, T. Drewa, P. Jarzemski,

P. Radziszewski, M. Slojewski, A. Antoniewicz, A. Paradysz, P.L. Chlosta

cases of COVID-19 in Poland: a preliminary report. Med Sci Monit 2020; 26: e924702.

17. Hiremath P, Suhas Kowshik CS, Manjunath M, Shettar M COVID 19: impact of lock-down on mental health and tips to overcome. Asian J Psychiatr 2020; 51: 102088-8.

18. Wong L, Hawkind JE, Langness S, Murrell KL, Iris P, Sammann A. Where are all the patients? Addressing Covid-19 Fear to encourage sick patients to seek emergency care. NEJM Catalyst Innovations in Care Delivery 2020.

19. Reznik A, Gritsenko V, Konstantinov V, Khamenka N, Isralowitz R. COVID-19 fear in Eastern Europe: validation of the fear of COVID-19 scale. Int J Ment Health Addict 2020: 1-6. doi: 10.1007/s11469-020-00283-3.

20. Stein DJ, Lim CCW, Roest AM, et al. The cross-national epidemiology of social anxiety disorder: Data from the World Mental Health Survey Initiative. BMC Med 2017; 15: 143.

21. Dimitriu MCT, Pantea-Stoian A, Smaranda AC, et al. Burnout syndrome in Romanian medical residents in time of the COVID-19 pandemic. Med Hypotheses 2020;144: 109972.

22. Burlacu A, Mavrichi I, Crisan-Dabija R, Jugrin D, Buju S, Artene B, Covic A. "Celebrating old age": an obsolete expression during the COVID-19 pandemic? Medical, social, psychological, and religious consequences of home isolation and loneliness among the elderly. Arch Med Sci 2020; 17: 285-95. 